0040-4039(95)02120-5

\title{
A Mild Palladium(II) Catalyzed Desilylation of Phenolic $t$-Butyldimethylsilyl Ethers
}

\author{
Noel S. Wilson and Brian A. Keay* \\ Department of Chemistry, University of Calgary, Calgary, Alberta, Canada, T2N 1N4
}

\begin{abstract}
A variety of phenolic $t$-butyldimethylsilyl ethers are easily removed in good to excellent yields by treatment with $5 \mathrm{~mol} \% \mathrm{PdCl}_{2}\left(\mathrm{CH}_{3} \mathrm{CN}\right)_{2}$ in refluxing acetone containing 5 equivalents of
\end{abstract} water.

Since it was first reported in $1972,{ }^{1}$ the $t$-butyldimethylsilyl (TBDMS) moiety has become one of the most widely used protecting groups for primary and secondary aliphatic alcohols. ${ }^{2}$ Its use as a protecting group for phenols, however, has not been as widely accepted, presumably, since a) removal with common reagents, such as $n$ - $\mathrm{Bu}_{4} \mathrm{NF} / \mathrm{THF}$, can lead to complex mixtures due to the basicity of the reagents ${ }^{3}$ and b) aqueous workup can lead to diminished yields of some phenols due to their water solubility. Although many methods have been developed for the removal of the TBDMS group from aliphatic alcohols, ${ }^{2}$ to our knowledge, only four methods have been reported for the cleavage of TBDMS phenolic ethers. ${ }^{3-6}$ These are the use of: a) aq. $\mathrm{HF} / \mathrm{NaF} ;{ }^{3}$ b) $48 \% \mathrm{HBr}, t$-BuBr, $\mathrm{KF} ;{ }^{4}$ c) $37 \% \mathrm{KF}$-basic alumina with ultrasound $;^{5}$ and d) neutral alumina in a microwave. ${ }^{6}$ While each of the above methods has their own merit, there are some drawbacks. Method a) was performed only on one example, method b) requires the use of a strong acid which other functional groups in the molecule may not tolerate, and methods c) and d) require the use of nonstandard laboratory equipment (ultrasound and a microwave). Thus, we have developed, and report herein, a new method for the removal of TBDMS phenolic ethers, which uses conventional laboratory equipment, is performed in a neutral medium, does not require an aqueous workup, and tolerates a variety of functional groups.

While developing a palladium catalyzed cross-coupling reaction, ${ }^{7}$ we found that in one example a TBDMS protected phenol was cleaved to the corresponding phenol in good yield when treated with catalytic amounts of $\mathrm{Pd}\left(\mathrm{PPh}_{3}\right)_{4}$ in a toluene $/ \mathrm{H}_{2} \mathrm{O} / \mathrm{Na}_{2} \mathrm{CO}_{3}$ mixture at reflux. A search of the literature indicated that Lipshultz and co-workers ${ }^{8}$ had reported that catalytic quantities of $\mathrm{PdCl}_{2}\left(\mathrm{CH}_{3} \mathrm{CN}\right)_{2}$ in acetone at r.t. removed a primary aliphatic TBDMS ether in 99\% yield; however, it was not mentioned whether phenolic TBDMS ethers could be cleaved under similar conditions. 
Table 1. Desilylation Results Using A Variety of Conditions with 3-(t-Butyldimethylsilyloxy)Benzaldeyde.

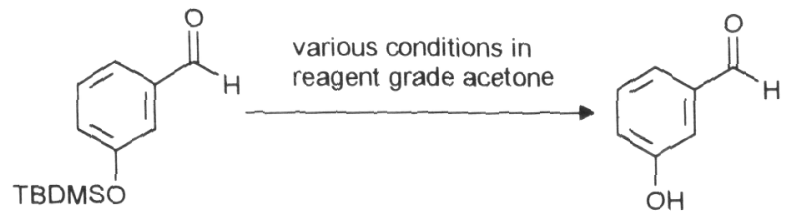

\begin{tabular}{|c|c|c|c|c|c|c|c|}
\hline \hline Entry & Scale & $\begin{array}{c}\text { Amount of } \\
\mathbf{P d C l}_{2}\left(\mathbf{C H}_{3} \mathbf{C N}\right)_{2}\end{array}$ & Time (h) & $\begin{array}{c}\text { Temp. } \\
\left({ }^{0} \mathbf{C}\right)\end{array}$ & Solvent ${ }^{\text {a }}$ & $\begin{array}{c}\text { Amount of } \\
\mathbf{H}_{2} \mathbf{O}\end{array}$ & Yield (\%) $^{\mathbf{O}}$ \\
\hline 1 & $350 \mathrm{mg}$ & $5 \mathrm{~mol} \%$ & 16 & 75 & acetone & 5 equiv. & 76 \\
\hline 2 & $313 \mathrm{mg}$ & $1 \mathrm{~mol} \%$ & 19 & 75 & acetone & 5 equiv. & 74 \\
\hline 3 & $260 \mathrm{mg}$ & none & 120 & 75 & acetone & 5 equiv. & $16^{c}$ \\
\hline 4 & $303 \mathrm{mg}$ & $5 \mathrm{~mol} \%$ & 30 & 75 & acetone & none & $10^{c}$ \\
\hline 5 & $3 \mathrm{~g}$ & $5 \mathrm{~mol} \%$ & 18 & 75 & acetone & 5 equiv. & 72 \\
\hline
\end{tabular}

a) Reagent grade acetone purchased from Van Waters and Rogers/Canlab (Edmonton, AB., Canada) was used.

b) Isolated yields.

c) Heavy decomposition noted.

We have found that a variety of phenolic $t$-butyldimethylsilyl ethers are easily removed in good to excellent yields by treatment with $1-5 \mathrm{~mol} \% \mathrm{PdCl}_{2}\left(\mathrm{CH}_{3} \mathrm{CN}\right)_{2}$ in refluxing reagent grade acetone containing 5 equivalents of water (Tables 1 and 2). As Table 1 indicates, $1-5 \mathrm{~mol} \%$ of $\mathrm{PdCl}_{2}$ can be used, however, the reaction takes longer when less $\mathrm{PdCl}_{2}$ is used (compare entries 1 and 2). It has also been shown that the palladium catalyst and water are necessary for a successful reaction. In the absence of catalyst, a $16 \%$ yield of 3-formylphenol was obtained after refluxing the mixture for 5 days (entry 3). A similar poor yield $(10 \%)$ was obtained in the absence of water after refluxing for $30 \mathrm{~h}$ (entry 4$)$. In both cases, heavy decomposition was noted. Five equivalents of water appears to be the optimum amount for this reaction. The reaction takes longer when less water is used and the workup can be difficult if more water is used due to the solubility of some phenols in water. The optimized reaction conditions lend themselves to a large scale reaction. Thus, 3 grams of 3-(t-butyldimethylsilyloxy)benzaldehyde provided a $72 \%$ yield of 3 formylphenol after refluxing the mixture for $18 \mathrm{~h}$ (entry 5). The workup of this reaction is very simple and does not require an aqueous phase wash. After t.l.c. or G.C. indicates that the silyl group has been removed, the mixture is filtered through Celite and the acetone and small amount of water is removed on a rotoevaporator to leave a residue which is purified by either distillation or recrystalization. 
Table 2. Results From The Desilylation Of Various Phenolic Silyl Ethers With 5 mol\% $\mathrm{PdCl}_{2}\left(\mathrm{CH}_{3} \mathrm{CN}\right)_{2}$.

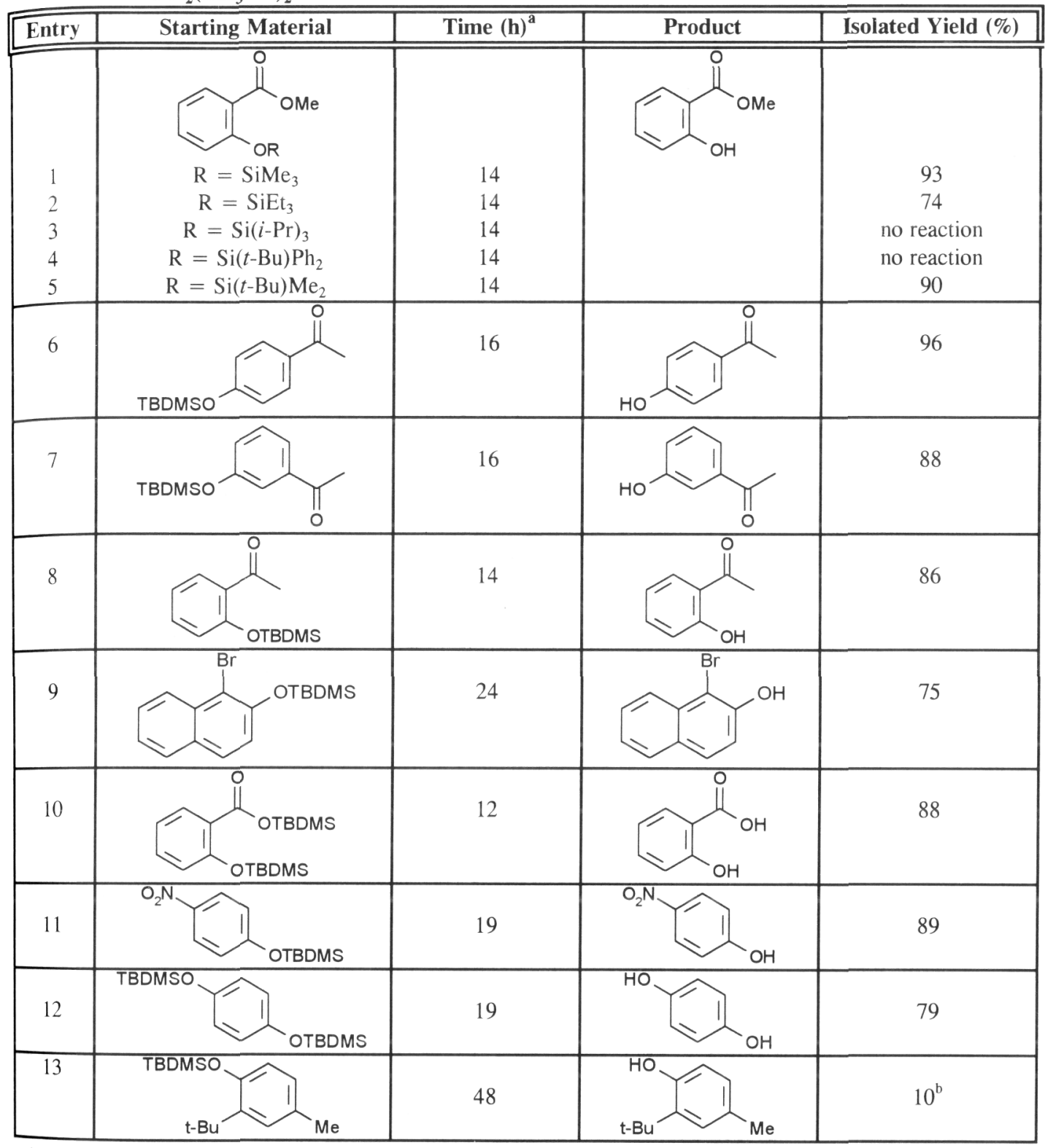

a) All reactions were performed in reagent grade acetone containing 5 equivalents of water at $75^{\circ} \mathrm{C}$.

b) The remainder was unreacted starting material. 
In addition to the removal of the TBDMS ether, the optimized desilylation conditions also removed trimethyl- (TMS) and triethyl-silyl (TES) protected phenols (Table 2, entries 1 \& 2); the tri-i-propyl(TIPS) and $t$-butyldiphenyl-silyl (TBDPS) phenolic ethers were not affected (entries $3 \& 4$ ). Thus, TMS, TES, and TBDMS phenolic ethers can be selectively removed in the presence of TIPS and TBDPS phenolic ethers. Finally, a number of functional groups were tolerated during this reaction (Table 1 and Table 2). TBDMS phenolic ethers were cleaved in yields ranging from 76-96\% in the presence of aldehydes, ketones, esters, a bromide and a nitro group; however, the reaction was sluggish when the OTBDMS group was hindered by an ortho-t-butyl group (Table 2, entry 13).

We have developed a simple, inexpensive, neutral procedure for the desilylation of TBDMS (and TMS and TES) phenolic ethers in good to excellent yields, which uses conventional laboratory equipment and does not require an aqueous workup. Experiments to understand further the mechanism of this desilylation are currently in progress.

\section{Typical Experimental}

To a mixture of 4-( $t$-butyldimethylsilyloxy)acetophenone $(256 \mathrm{mg}, 1.02 \mathrm{mmol})$, water $(9.21 \mu \mathrm{L}, 5.11$ mmol, 5 equiv.) and acetone $(1.25 \mathrm{~mL})$ was added $\mathrm{PdCl}_{2}\left(\mathrm{CH}_{3} \mathrm{CN}\right)_{2}(13.3 \mathrm{mg}, 0.0511 \mathrm{mmol}, 5 \mathrm{~mol} \%)$. The mixture was refluxed $\left(75^{\circ} \mathrm{C}\right.$ ) for 16 hours (followed by $\mathrm{GC}$ ), cooled to room temperature, filtered through Celite, and the acetone and water removed on a rotoevaporator to leave a solid. Distillation of the solid $\left(100-110^{\circ} \mathrm{C} / 0.01\right.$ torr) provided 4-hydroxyacetophenone in $92 \%$ yield.

\section{Acknowledgements}

We thank the Natural Sciences and Engineering Research Council of Canada and The University of Calgary for financial support and Dr.'s S.P Maddaford and I. R. Hunt for their initial desilylation results.

\section{References and Notes}

1. Corey, E.J.; Venkateswarlu, A. J. Am. Chem. Soc. 1972, 94, 6190.

2. Greene, T.W.; Wuts, P.G.M. Protective Groups in Organic Synthesis, 2 Ed., John Wiley and Sons, Inc., New York, 1991.

3. Kendall, P.M.; Johnson, J.V.; Cook, C.E. J. Org. Chem. 1979, 44, 1421.

4. a) Sinhababu, A.K.; Kawase, M.; Borchardt, R.T. Synthesis 1988, 710. b) Sinhababu, A.K.; Kawase, M.; Borchardt, R.T. Tetrahedron Lett. 1987, 28, 4139.

5. Schmittling, E.A.; Sawyer, J.S. Tetrahedron Lett. 1991, 32, 7207.

6. Varma, R.S.; Lamture, J.B.; Varma, M. Tetrahedron Lett. 1993, 34, 3029.

7. Maddaford, S.P.; Keay, B.A. J. Org. Chem. 1994, 59, 6501.

8. Lipshutz, B.H.; Pollart, D.; Monforte, J.; Kotsuki, H. Tetrahedron Lett. 1985, 26, 705. 